\title{
An Exploratory Analysis of Joint-Activity Participation Characteristics Using the American Time Use Survey
}

\author{
Sivaramakrishnan Srinivasan* \\ University of Florida \\ Department of Civil and Coastal Engineering \\ 365 Weil Hall, PO Box 116580 \\ Gainesville, FL 32608 \\ Tel: 352-392-9537 Extn. 1456 \\ Fax: 352-392-3394 \\ E-mail: siva@ce.ufl.edu \\ and \\ Chandra R. Bhat \\ The University of Texas at Austin \\ Dept of Civil, Architectural \& Environmental Engineering \\ 1 University Station C1761 \\ Austin, TX 78712-0278 \\ Tel: 512-471-4535 \\ Fax: 512-475-8744 \\ E-mail: bhat@mail.utexas.edu \\ ${ }^{*}$ corresponding author
}




\section{ABSTRACT}

This paper presents a detailed exploratory analysis of joint activity participation characteristics using the American Time Use Survey (ATUS). As a very large nationwide survey that explicitly elicited information on both household and non-household companions for each activity episode, the ATUS is ideally suited for this analysis. Several intuitive and interesting results are obtained. Joint episodes are found to be of longer durations, significantly likely to take place at the residence of other people, and often confined to certain time periods of the weekday. In addition, important differences in these characteristics are also observed based on activity purpose, companion type, and the day of the week. These findings are intended to provide the basis for the justification of detailed collection of joint activity-travel participation information in household activity-travel surveys, and also as a stimulant for further empirical analysis and modeling of joint activity participation behavior.

\section{KEY WORDS}

Joint Activities and Travel, American Time Use Survey, Non-household Companions 


\section{BACKGROUND AND OBJECTIVES}

Individuals undertake both independent and joint activities/travel as part of their overall daily activity-travel patterns. The joint activity pursuits are often motivated by social factors such as desire for companionship and altruism (i.e., enabling activity participation of the mobilityconstrained) and resource constraints (i.e., limited vehicle availability). Undertaking joint activities with household and/or non-household members introduces strong linkages among the activity-travel patterns of the individuals involved. Such inter-personal inter-dependencies should be explicitly accommodated in travel demand models for realistic planning and policy evaluation. For example, joint participation in activities explicitly "links" the travel patterns of different individuals. Consequently, it is possible that the travel pattern of an individual changes because of a transportation policy action that affects the activity-travel behavior of his/her companion. These secondary impacts cannot be captured by models that do not accommodate inter-personal inter-dependencies. In addition, vehicle occupancy (which is very important from the standpoint of evaluating strategies such as HOV lanes) is determined by decisions of individuals to travel together, which in turn could be motivated by the desire to participate in the destination activity jointly. Further, the nature and number of companions in the party could influence the choice of the vehicle type. The composition of vehicles by type in the network has implications for the levels of congestion and emissions. Finally, individuals may be willing to travel farther and pursue activities for longer durations when the activity/travel is being pursued jointly with family or friends (see Srinivasan and Bhat, 2006a and Vovsha et al., 2003 for further discussion on the practical importance of modeling joint activities and travel).

In recognition of the above-discussed issues, there has been increasing efforts in the field of transportation engineering on studying and accommodating inter-personal interdependencies in activity-travel patterns. These earlier efforts may be broadly classified into two categories, as discussed below.

The first category of studies broadly view "jointness" in activity participation as an additional attribute of activity-travel patterns (just like mode, time-of-day, location, etc.). Econometric modeling methods are adopted to relate the decision of undertaking a joint versus solo activity with characteristics of the decision makers (see Srinivasan and Bhat, 2006b and the studies referred to therein for additional details). Most of these studies use data from conventional activity-travel surveys and only a few have examined participation in joint activities or travel with non household members. For example, Chandrasekharan and Goulias (1999) used panel data from the Puget Sound region to study joint travel undertaken with household members, non-household family members, and other "outsiders". Similarly, the ALBATROSS 
model system (Arentze et al., 2000) also models the household and non-household members included in the travel party. Kapur and Bhat (2007) use the American Time Use Survey to examine the weekend discretionary activity participation patterns with both household and nonhousehold members. Goulias and Kim (2005) examine joint pursuits of both activities and travel using data on approximately 1500 individuals from the CenterSIM survey.

The second category of studies addresses the social dimension of activity-travel behavior by explicitly recognizing that a desire for companionship is an important stimulus for activity-travel generation. These studies are largely focused on the concept of "social networks" and explore the nature and extent of individuals' social interactions within and beyond households (See for example, Axhausen, 2005, Arentze and Timmermans, 2006, and Carrasco et al., 2006 for additional details).

Despite an increasing interest in recent years in the form of studies in the two categories identified above, our empirical knowledge on joint-activity participation characteristics of individuals (especially with non household members) is limited, arguably due to data reasons. Conventional activity-travel surveys often do not identify the activity and travel companions explicitly, hence requiring the analyst to use operational definitions based on space-time matches in the activity-travel patterns of individuals of a household to identify joint episodes (see for example, Gliebe and Koppelman, 2002 and Srinivasan, 2004). However, such a matching procedure cannot be used in identifying individuals' non-household companions in activity/travel participation. In recognition of this issue, some of the more recent and advanced travel surveys such as the CenterSIM (Goulias and Kim, 2005) and the CHASE (Doherty, 2006) explicitly include questions on the companions involved in activity participation. Further, the rather aggregate activity-type classification schemes often adopted in conventional activitytravel surveys do not allow the identification of important differences in companion-type choices, especially among the different kinds of "discretionary" or "leisure" activities.

In light of these discussions, the broad goal of this study is to contribute to the empirical understanding of activities and travel pursued by individuals jointly with household and nonhousehold members. Toward that end, a detailed exploratory analysis is undertaken using data from the American Time Use Survey (ATUS). The analysis aims to quantify the extent of joint activities and travel, and illustrate the differences in activity participation characteristics based on companion type and activity purpose. Finally, differences in joint activity participation patterns between weekdays and weekend days are also highlighted. 


\section{DATA}

This research study uses data from the American Time Use Survey (ATUS). The ATUS is conducted by the Census Bureau under contract with the Bureau of Labor Statistics and collects detailed individual-level daily time use information. The sample is drawn from a subset of households responding to the Current Population Survey (CPS) interviews. One individual aged 15 years or older is selected from each sampled household for the survey. Data collection began in January 2003 and has continued yearly since. For the current paper, data samples collected in the years 2003 (412,611 activity episodes from 20,000 individuals) and 2004 (279,042 activity episodes from 13,973 individuals) are used. Additional details on the ATUS survey and the resulting data can be obtained from the ATUS website, http://www.bls.gov/tus/home.htm.

The ATUS data is appealing for our analysis for several reasons. First, the available data sample is very large (34,693 persons surveyed over 2 years) and represents the nation as a whole rather than any specific geographic region. Second, the survey explicitly obtains information on all persons (both household and non-household members) accompanying the respondent for each activity episode. A disaggregate classification scheme is used for the companion types (such as parent, sibling, non-household family member, friends, colleagues/clients, and acquaintances). Third, the survey uses a very disaggregate three-tier activity classification scheme, facilitating the analysis of joint activity participation at a fine resolution of activity purposes.

\section{EMPIRICAL ANALYSIS}

This section of the paper discusses the empirical analysis results. First, we present a person-level analysis of the daily volume (episode frequency and total duration) of activities and travel undertaken with different types of companions. The next set of analyses is at the episode level. The companion-type choice for activity and travel episodes (by activity /trip purpose) is examined first. Subsequently, we examine the differences, by companion type, in each of (1) the durations of activity and travel episodes, (2) the location of activity episodes, and (3) the time-of-day of participation in activity episodes. Finally, the sequencing of the activity and travel episodes is described.

It is important to emphasize here that the intent of this paper is to present an exploratory analysis of several facets of joint activity and travel participations rather than undertake detailed modeling of few dimensions. Thus, we use simple econometric methods in our models. All reported parameter estimates are statistically significant at the $90 \%$ level or higher. The ' $t$ ' 
statistics of the parameter estimates are, however, not provided in the empirical results tables to reduce clutter. We envision that the exploratory results presented here will aid the future development of activity-travel modeling systems that incorporate joint activity-travel participation of individuals with both household and non-household members.

\section{Daily, Person-level Activity and Travel Volumes by Companion Type}

Table 1 presents the aggregate sample characteristics of the daily, person-level, out-ofhome activity and travel participations by companion type (the companion types used in the table are "solo", "with only household members", "with only non-household members", and "with a combination of household and non-household members"). The results are separately provided for weekdays and weekends, and indicate the percentage of individuals who participate in one or more episodes (\%>=1 Episode) with each type of companion as well as the mean number of episodes and the average daily duration with each companion type (conditional on undertaking at least one episode with the corresponding type of companion). Several interesting observations can be made from these statistics. First, across weekday and weekends, a higher percentage of individuals participate in out-of-home activity and travel episodes solo (i.e., alone) than in any other type of companion arrangement (see the higher values of the numbers in the row labeled "\% >= 1 Episode" in the first column compared to the remaining three columns). At the same time, it is indeed interesting to note that almost one-third of individuals undertake one or more out-of-home $(\mathrm{OH})$ activity and travel episodes with household members on weekdays, and about $50 \%$ of individuals pursue $\mathrm{OH}$ activity episodes with non-household companions on weekdays. This indicates a rather high prevalence of joint participations even on weekdays. Second, the individuals undertaking joint activity and travel episodes on weekend days, on an average, undertake more of such episodes compared to those pursuing joint activities and travel on weekdays (irrespective of the companion type). In contrast, the average frequency of solo activity/travel participation is higher during weekdays compared to weekend days (3.25 versus 2.34 for $\mathrm{OH}$ activities and 3.55 versus 3.14 for travel episodes). Third, the average daily time investment in joint activities is substantially higher for weekend days compared to weekdays (again, for each companion type) and the opposite is found to be true for solo activities and travel. Specifically, the reader will note that the weekend joint activity durations are almost twice as much as the corresponding weekday durations and the weekend travel durations are one-and-a-half times the weekday travel durations. Further, during weekends, and again in contrast to weekdays, individuals also spend more time traveling with companions than traveling alone. Fourth, more people undertake one or more $\mathrm{OH}$ episodes and travel with only 
household members on weekend days than on weekdays (35.42\% versus $30.3 \%$ for OH activity episodes and $42.38 \%$ versus $35.81 \%$ for travel episodes). On the other hand, more people undertake one or more $\mathrm{OH}$ activity episodes with only non-household members during a weekday than the weekend (49.03\% versus $37.47 \%)$. Household members are separated from each other for a good part of weekdays because of mandatory activities such as work and school, thereby limiting possibilities for joint activity participation. At the same time, individuals are also in greater contact with non-household members such as friends, colleagues, and other acquaintances during the weekdays. This serves to explain the higher participation with household companions for weekend $\mathrm{OH}$ activity episodes, and the higher participation with only non-household companions for weekday $\mathrm{OH}$ activity episodes. Fifth, we also find that individuals are more likely to undertake weekend activities than weekday activities with a mixed composition of household and non-household members $(28.78 \%$ versus $17.52 \%$ for $\mathrm{OH}$ activity episodes and $12.02 \%$ versus $7.48 \%$ for travel episodes). In summary, the aggregate, daily, person-level statistics presented in Table 1 reflect the large extent to which individuals pursue daily activity and travel episodes with companions on both weekdays and weekend days.

Table 2 presents the results from ordered probit models developed to determine the number of daily episodes $(0,1,2,3,4$, and >=5) undertaken with each of the four different companion types. Individuals from single-person households cannot have household members as companions and hence are included only in the models where the companion type is either "solo" or "only non-household members". Separate models are developed for weekdays and weekend days and for activity and travel episodes. We find that men are more independent in their activity-travel pursuits than women, and undertake fewer $\mathrm{OH}$ activity and travel episodes with companions (see the row labeled "male" in the weekday and weekend day tables). The only exception is that men undertake more weekend $\mathrm{OH}$ activity episodes with non-household members relative to women. Further, and in general, students and employed individuals undertake more solo activity and travel episodes, more episodes with only non-household members, and fewer episodes with household members (during weekdays) relative to individuals who are not students or employed. The results also indicate a higher propensity to participate in solo activity and travel episodes for individuals with a high income and who are single (relative to individuals with a low income and who are non-single, respectively). Finally, we find that married individuals (relative to other individuals) undertake fewer episodes either solo or with only non-household members, and more episodes with only household members and with a combination of household and non-household members. These effects are further strengthened with the presence of children in the household. These results suggest the tighter 
intra-household interactions in activity and travel patterns among members of married families with children, a natural consequence of increased responsibility sharing as well as joint activity/travel pursuits.

\section{Companion Type for OH Activity and Travel Episodes}

Table 3 presents the results of multinomial logit (MNL) models for companion-type choice for $\mathrm{OH}$ activity episodes. The companions are broadly classified into the following eight categories: solo (no companions), only household children (age $<=17$ years), only household adults, only household children and adults, only family members not living in household (for example, grandparents), only friends (also includes colleagues and clients), only other nonhousehold members (such as neighbors and acquaintances), and combinations of nonhousehold and/or household members. Separate models were estimated for each activity purpose accommodating full segmentation by weekday and weekend days. The activity purpose and the household structure of the person undertaking the episode define the availability of the different choice alternatives (i.e., companion types). Specifically, social and serve passenger episodes, by definition, cannot be undertaken solo. Persons from households without children cannot have children as activity companions (alternatives "children" and "children \& adult" are not available) and if the person is the only adult in the household (as in single person and single parent households), then he/she does not have the alternatives "adult" and "children \& adult" available. All types of non-household companions are assumed to be available to all persons. Finally, it is useful to note here that ATUS assumes work episodes as being undertaken solo and hence work episodes are not included in this analysis.

Table 3 presents the parameter estimates of the utility functions. The "solo" category is taken as the base alternative except in the case of models developed for social and servepassenger purposes (as indicated earlier, episodes for social and serve passenger activity purposes cannot be pursued alone, and so the "only household children" category is used as the base category for these two purposes). Several broad inferences can be drawn from the MNL models. First, episodes for purposes other than social and serve-passenger are, in general, more likely to be undertaken solo than with any type of companions (as evidenced by the negative signs on the coefficients corresponding to almost all the non-solo companion types). The exceptions are weekday eat/drink episodes (which are most likely to be undertaken with friends), and weekend episodes for volunteer/religious and eat/drink purposes (which are most likely to be undertaken with a combination of household and non-household members). The result that eat/drink episodes are more likely to be undertaken jointly than independently 
suggests that such activities cannot be construed as purely for the purposes of physiological maintenance. Hence caution must be exercised in analyzing activity-travel behavior in terms of traditionally used activity-purpose classifications (See Doherty, 2006), and in particular, when aggregating purposes into one of mandatory, maintenance, and discretionary as often done in activity-travel analysis. Second, joint episodes for $\mathrm{HH} /$ personal chores and shopping (maintenance and other) are more likely to be pursued with household members (especially children) than non-household members, irrespective of the day of the week. This appears reasonable given the household/personal orientation of these activity purposes. Third, joint episodes for passive leisure and active leisure are more likely to involve friends than other companion types, regardless of day of the week. Passive leisure corresponds to pursuit of activities such as going to the movies or attending a sports event. This is opposed to active leisure which involves activities such as exercising or playing sports. Note also that passive leisure episodes on both weekdays and weekend days are equally likely to be undertaken either solo or with friends. Fourth, social episodes are most likely to be pursued with friends on weekdays and with a combination of household and non-household members on weekend days. Fifth, all the discretionary activities (passive leisure, active leisure, volunteer/religious, eat and drink, and social episodes) are not very likely to be undertaken along with children. Finally, when children are present in the household, they are the most likely companions for servepassenger activity episodes. Individuals without children are more likely to escort nonhousehold members such as family and friends or a combination of household and nonhousehold members than only household members.

Table 4 presents the results of corresponding MNL models for companion type choice for travel episodes. The household structure of the person undertaking the episode defines the availability of the different choice alternatives (i.e., companion types) in the same way as discussed in the context of the model for companion types for activity episodes. The availability of alternatives is, however, not determined by the purpose of the destination activity (since an individual can travel alone to participate in a social activity or to pick-up a passenger). Thus, the "solo" companion type is used as the reference category in all the models. The results in Table 4 show that, as in the case of $\mathrm{OH}$ activity episodes, travel episodes are also more likely to be undertaken solo than jointly with companions irrespective of the trip purpose and day of the week. The only exceptions are weekday serve passenger episodes (which are most likely to have children as companions) and weekend travel for eat/drink (which are most likely to be undertaken with other household adults). Joint-travel, in general, is more likely to be undertaken with only household members or with a combination of household and non-household members 
than with only non household members. The only exception is the joint weekday travel for work/school purposes, which are most likely to have friends (including colleagues) as travel companions. Note that these trips could be either formal carpooling arrangements for the homework commute or other work-based travel including the return-to-work trips from lunch with colleagues. Finally, when travel is undertaken with non-household members for leisure activities, the companions are likely to be friends.

An important dimension of joint travel that is of direct relevance to transportation planning in the context of evaluating HOV lanes is the number of travelers in the vehicle. In the case of travel undertaken with only children, approximately $65 \%$ (averaged over all trip purposes) of the trips involve travel with one child, $26 \%$ involve two children and the rest have three or more children in the travel party. These hold for both weekdays and weekend days. On the other hand, when travel is undertaken with only household adults, approximately $98 \%$ (averaged over all trip purposes) of the weekday trips and $96 \%$ of weekend trips have just one travel companion (or equivalently two persons in the vehicle). For trips undertaken with "both household children and adults" or with "a combination of household and non household members", there are at least two travel companions (or three persons in the vehicle) by definition. For travel undertaken with only non-household members (family, friends, or other), the ATUS data do not provide us with the number of persons in the travel party.

\section{Activity and Travel Episode Durations by Companion Type}

Table 5 presents regression models for activity-episode duration. The logarithm of the episode duration is taken as the dependent variable. The companion type for the episode ("only children" is taken as the base category for social and serve passenger episodes and "solo" is taken as the base category for other activity purposes) and the characteristics of the traveler are included as explanatory variables. Separate models are developed for each activity purpose and for weekdays and weekend days. The results reconfirm our intuitive expectation that joint episodes are on an average of higher durations compared to solo episodes (see the positive coefficients corresponding to the companion type variables). The only exception is for maintenance shopping undertaken with friends, which are shorter in duration than solo episodes for the same purpose. Further, we also find that maintenance shopping episodes undertaken with household companions are of longer durations than when undertaken with non household companions. Among joint episodes undertaken with household members, those undertaken with only children are, in general, of shorter durations than those undertaken with only adults or a combination of adults and children. Within the category of leisure activities, passive leisure 
episodes jointly undertaken with only household members are of longer durations than those undertaken with non-household members. The opposite holds for active leisure episodes. That is, joint episodes with non household members for active leisure are of longer durations than those with household members. There is little variability in the duration of serve-passenger episodes. However, we do find that episodes to pick-up/drop-off only children are of longer durations than those to serve adults. Further, if multiple persons are present in the party (i.e., combination of companion types) then the corresponding serve-passenger episodes are of the longest duration.

Table 6 presents similar regression models for travel-episode duration. The logarithm of the episode duration is taken as the dependent variable. The companion type for the episode ("solo" is taken as the base category), characteristics of the traveler, and the travel mode are included as explanatory variables. Separate models are developed for each trip purpose (or destination activity purpose) and for weekdays and weekend days. As in the case of activity episodes, we find that travel episodes undertaken with companions are of longer durations than those undertaken solo. There are two exceptions. First, weekday solo trips to work are of longer durations than those undertaken with companions. Second, weekday serve-passenger and return-home trips undertaken with only children are of shorter durations than solo trips of the corresponding purposes. Among joint travel episodes, those undertaken with only children are also, in general, the shortest.

In summary, the regression models presented in Tables 5 and 6 suggest significant effects of companion type on the activity and travel durations, even after controlling for trip purpose, mode, and traveler characteristics. It is useful to note here that the impacts of traveler characteristics (such as gender, employment characteristics, household structure, presence of children, and income) on activity-travel durations have been well documented in the literature.

\section{Activity Episode Locations by Companion Type}

For the purposes of this analysis, out-of-home activity locations have been broadly classified into work/school, someone else's home, and other locations. Table 7 presents MNL models for the choice of location for joint out-of-home episodes undertaken with non-household members. In the case of episodes undertaken with household members, the "other location" dominates all location categories, and hence the focus here only on episodes undertaken with non-household members. The companion types are taken as the explanatory variables, and models are developed for the four $\mathrm{OH}$ activity purposes of serve passenger, eat/drink, social, and passive leisure categories. For the other out-of-home activity purposes (i.e., $\mathrm{HH}$ /personal 
chores, maintenance shopping, other shopping, volunteer/religious, and active leisure), the "other location" generally dominates all location categories

The results indicate that out-of-home activity episodes not undertaken exclusively with friends, and for serve-passenger, social, and passive leisure episodes, are highly likely to be undertaken at "someone else's home". These results provide additional empirical evidence to support the claim (Carrasco et al., 2006 and Kemperman et al., 2006) that individuals are perhaps not very flexible in their choice of destination location for the pursuit of discretionarytype activities undertaken with non-household companions. On examining the weekday episodes for eat/drink, social, and passive leisure purposes undertaken with friends, we find that these are most likely to be undertaken at a work/school location. This suggests that time spent at work/school is not entirely for mandatory pursuits. The nature and extent of social contact at work/school may significantly influence the overall activity-travel behavior of individuals and hence merits further analysis.

\section{Time-of-Day of Participation in Non-Work Activity Episodes by Companion Type}

In this section, we discuss the temporal characteristics of out-of-home non-work activity participation by companion type (Note that work/school episodes are necessarily taken to be solo in our analysis). Further, for the sake of conciseness, the analysis is performed on the aggregate category of non-work activities (Kemperman et al., 2006 provide a similar analysis by activity type; however they do not distinguish among companion types).

Table 8 presents multinomial logit models for the choice of time-of-day for non-work activity participation. The period from 7 AM to 9 PM is divided into seven two-hour periods. In addition, the periods before $7 \mathrm{AM}$ and after 9 PM are taken as two longer discrete periods resulting in a total of nine discrete periods for the day. Separate models are estimated for weekdays and weekend days and for episodes undertaken with each type of companion. The period before $7 \mathrm{AM}$ is considered as the base category. The temporal profiles of non-work activity episodes by companion type are also presented in Figure 1 (weekday profiles) and Figure 2 (weekend day profiles). Several interesting observations can be made from these empirical results. First, almost all the model coefficients are positive indicating that individuals are more likely to pursue out-of-home activities after 7 AM than before 7 AM. The only exceptions are (1) solo activity participation on both weekdays and weekend after 9 PM days is less likely than before 7 AM, and (2) activity participation with only children on weekdays after 9 PM is less likely than before 7 AM. Second, weekday activities with only children are most likely to begin during the 7-9 AM period or during the 3-5 PM period (See also the profiles in Figure 
1). This bi-modal profile appears reasonable as these periods include the typical school startand end-times. Third, a similar bi-modal profile also applies to episodes undertaken with other adults in the household during weekdays, though the peaks for this profile correspond to the midday period (11 AM - $1 \mathrm{PM}$ ) and the early evening period (5 - $7 \mathrm{PM)}$. Fourth, the early evening periods during weekdays also appear to be the most likely time for joint activity participation with a combination of companion types (either with a combination of household children and adults or with a combination of household and non-household members). As mandatory (work/school) activity pursuits of all individuals are typically completed by this time, the early evenings are perhaps ideal for scheduling the joint activities involving several people. $\underline{\text { Fifth}}$, joint-activity participation with only friends/colleagues peak during the mid-day period (11am -1pm). This is consistent with individuals' mid-day break from work/school activities. Note that the solo non-work activity participation during weekdays also peaks during the same period. Sixth, weekend activity participations do not exhibit the weekday peaking characteristics. Specifically, note that, for each companion type, there is very limited variability in the values of the model coefficients across the five discrete periods from $9 \mathrm{AM}$ to $7 \mathrm{PM}$. The same result is illustrated graphically in Figure 2.

In summary, joint activity participation requires temporal synchronization among multiple persons. During weekends, the relative lack of time constraints imposed by the work activity allows people to be more flexible in their choice of time-of-day for joint episodes. On the other hand, during weekdays, joint episodes are confined to certain periods of the day depending on the type of the accompanying persons. Recognizing such behavioral patterns is important from the standpoint of evaluating demand-management policy actions such as work staggering. Specifically, such measures could also change the travel patterns of persons not directly exposed to the policy because of their desire to pursue activities and travel jointly with individuals who are directly affected by the policy action.

\section{Sequencing of Activity and Travel Episodes}

This final section of the empirical analysis examines the sequencing of episodes. For this purpose, all episodes are classified into one of in-home, out-of-home solo, out-of-home with only household members, out-of-home with non-household members, serve-passenger, solo travel, travel with only household members, and travel with non-household members. The sequencing is examined in terms of the state dependence effects between consecutive activity episodes. Transition matrices (Table 9) of activity episodes are designed (separately for weekdays and weekends) to represent the likelihood that a subsequent episode of a certain 
type will occur given an episode of a current type. The rows represent the type of the current activity episode, while the columns indicate the type of the subsequent activity episode. The entries in each cell indicate the percentage of occurrence of an activity episode of the type indicated in the column subsequent to the activity episode of the type indicated in the row). For example, the value of 86.93 in the first cell implies that $86.93 \%$ of all weekday in-home episodes are succeeded immediately by another in-home episode. Note that the percentages sum to 100 for each row.

$\mathrm{OH}$ solo activity episodes are most likely to be succeeded by travel solo episodes on both weekdays and weekend days. The likelihood of an $\mathrm{OH}$ episode with non-household members immediately succeeding an $\mathrm{OH}$ solo episode decreases from weekdays (15.06\%) to weekends (10.53\%). In the context of weekdays, such transitions could represent independent work followed by a joint episode with friends/colleagues for lunch. Out-of-home episodes undertaken with only household members are most likely to be succeeded by a joint travel episode with household members (76.50\% for weekdays and $77.36 \%$ for weekend days). In contrast, $\mathrm{OH}$ episodes undertaken jointly with non-household members may be followed by either solo or joint travel episodes with non-household members, with the latter being more likely.

Serve passenger episodes are immediately followed by a travel episode (by definition). Further, the likelihood of travel with non-household members after a serve-passenger episode is significantly higher during weekend days than weekdays (39.30\% versus $22.86 \%$ ). The opposite is found to be true for travel with household members immediately following a serve-passenger episode. These statistics suggest that individuals are more likely to chauffer household members during weekdays and non household members during weekend days.

Solo travel episodes are most likely to be return-home trips or be immediately succeeded by a solo out-of-home episode. Further, we observe that solo trips for participating in $\mathrm{OH}$ episodes with non-household members is more likely during weekend days than weekdays. Joint trips with household members are very likely to be succeeded by $\mathrm{OH}$ episodes with household members. Similarly, Joint trips with non household members are very likely to be succeeded by $\mathrm{OH}$ episodes with non household members. These results suggest that a primary reason for joint travel with household or non household companions is perhaps to pursue $\mathrm{OH}$ activity episodes with those companions. Finally, the likelihood of undertaking travel purely for escorting reasons (i.e., a travel episode followed by a serve passenger) is higher during weekdays than weekends. This is possibly a manifestation of the serve-passenger episodes undertaken to chauffer children to/from school during the weekdays. 


\section{SUMMARY AND IMPLICATIONS}

It is now well recognized that incorporating inter-personal interactions in travel-demand modeling is important for realistic forecasts and policy evaluation. In this context, this paper sets the stage for more detailed empirical analysis and modeling of joint activities by presenting a detailed exploratory analysis. Specifically, this paper considers joint participation with both household and non-household members, and examines the generation, location, and scheduling of joint activity episodes. Such an exploratory analysis is a necessary first step in informing the development of activity-based travel demand models that adequately capture joint participation in activity and travel episodes.

The results of this analysis highlight the high levels of joint activity- travel participation by individuals. Further, independent activities are found to be different from joint activities in systematic ways. Specifically, joint episodes are of longer durations, significantly likely to take place at the residence of other people, and often confined to certain time periods of the weekday. In addition, within the class of joint episodes, important differences are also observed based on activity type, companion type, and the day of the week. Finally, we also find strong influence of socio-economic characteristics (such as gender, employment characteristics, household structure, presence of children, and income) on how individuals spend time with different types of companions. These variables have also been found to impact other dimensions of time-use in past studies.

Overall, the empirical results from this study highlight the important need to accommodate intra-household and inter-household interactions in activity-travel behavior analysis. Specifically, some of the key implications of our empirical findings include the following: First, given the sheer magnitudes of joint activity and travel engagement, our results underscore the need for travel demand models to recognize these inter-dependencies for accurate travel forecasts and policy analysis. Second, the timing (i.e., duration and time-of-day) of activity-travel is found to be related to the companion type. Consequently, accurate assessment of soak time distributions for air quality models requires information on joint activitytravel engagement patterns. Third, a high fraction of joint leisure-type activities is found to be undertaken at "someone else's home". The implication here is that individuals are perhaps not as flexible in their choice of destination location for the pursuit of discretionary activities. Fourth, the desire to participate in activities with non household members such as friends also generates additional travel to pick-up and drop-off the activity companions. Such travel cannot be realistically captured by individual-level models. Fifth, with the gaining prominence of the 
need to model weekend travel behavior, accommodating inter-personal interactions assumes even greater significance as joint activity and travel participation levels during weekends are found to be greater than those during weekdays. Finally, to enable the development of empirical models that accommodate inter-personal interdependencies, future travel surveys should be suitably enhanced to adopt a more disaggregate activity classification scheme and to collect data on individuals' activity and travel companions.

\section{ACKNOWLEDGEMENTS}

The authors would like to acknowledge the constructive feedback provided by reviewers on a previous version of this paper. The second author would like to acknowledge the support of an International Visiting Research Fellowship and Faculty grant from the University of Sydney. 


\section{REFERENCES}

Arentze, T., Hofman, F., Mourik, H., and Timmermans, H (2000) "ALBATROSS: Multiagent, rule-based model of activity pattern decisions", Transportation Research Record 1706, pp. 136-144.

Arentze, T. and Timmermans, H. (2006) "Social Networks, Social Interactions, and ActivityTravel Behavior: A Framework for Micro-Simulations". Presented at the $85^{\text {th }}$ Annual Meeting of the Transportation Research Board.

Axhausen, K.W. (2005) "Social Networks and Travel: Some Hypothesis". In Donaghy, K. (ed.) Social Aspects of Sustainable Transport: Transatlantic Perspectives, Aldershot, Ashgate.

Carrasco, J., Hogan, B., Wellman. B., and Miller, E.J. (2006) "Collecting Social Network Data to Study Social Activity-Travel Behavior: An Egocentric Approach", Presented at the $85^{\text {th }}$ Annual Meeting of the Transportation Research Board.

Chandrasekharan, B. and Goulias, K.G. (1999) "Exploratory Longitudinal Analysis of Solo and Joint Trip Making Using the Puget Sound Transportation Panel", Transportation Research Record, 1676, pp. 77-85.

Doherty, S (2006) "Should We Abandon Activity-Type Analysis? Redefining Activities by Their Salient Attributes" Transportation, Vol. 33, pp. 517-536.

Gliebe, J.P. and Koppelman, F.S. (2002) "A Model of Joint Activity Participation Between Household Members". Transportation, Vol. 29, pp. 49-72.

Goulias, K. G. and Kim, T. G. (2005) "An Analysis of Activity-Type Classification and Issues Related to the With Whom and For Whom Questions of an Activity Diary". In Timmermans, H. J. P. (ed.) Progress in Activity-Based Analysis, Elsevier, Oxford, England.

Kapur, A., and C.R. Bhat (2007), "On Modeling Adults' Daily Time Use by Activity Purpose and Accompaniment Arrangement," forthcoming, Transportation Research Record.

Kemperman, A., Arentze, T., and Timmermans, H (2006) "Social Commitments and ActivityTravel Scheduling Decisions", Presented at the $85^{\text {th }}$ Annual Meeting of the Transportation Research Board.

Srinivasan, S. (2004) "Modeling Household Interactions in Daily Activity Generation". PhD Dissertation, Department of Civil Engineering, The University of Texas at Austin.

Srinivasan, S. and Bhat, C.R. (2006a) "Companionship for Leisure Activities: An Empirical Analysis Using the American Time Use Survey". White paper presented at the Innovations in Travel Demand Modeling Conference, Austin, TX. Available from http://www.trb.org/Conferences/TDM/papers/BS3B\%20\%20Srinivasan_Bhat_Austin2006.pdf 
Srinivasan, S., and Bhat, C.R. (2006b) "A Multiple Discrete-Continuous Model for Independentand Joint- Discretionary-Activity Participation Decisions," Transportation, 2006 TRB Special Issue, Vol. 33, No. 5, pp. 497-515

Vovsha, P., Peterson, E., and Donnelly, R. (2003) "Explicit Modeling of Joint Travel by Household Members: Statistical Evidence and Applied Approach", Transportation Research Record 1831, pp 1-10. 


\section{List of Tables}

Table 1 Daily, Person-level Activity and Travel Participation: Descriptive Statistics

Table 2 Models for the Frequency of Daily, Person-level, Activity and Travel Episodes

Table 3 Companion-Type Choice Models for Out-of-Home Activity Episodes

Table 4 Companion-Type Choice Models for Travel Episodes

Table 5 Models for Out-of-Home Activity Episode Durations

Table 6 Models for Travel Episode Durations

Table 7 Location Choice Models for Out-of-Home Activity Episodes

Table 8 Time-of-Day Choice Models for Non-Work Activity Episodes

Table 9 Activity Episode Purpose Transition Matrix

\section{List of Figures}

Figure 1 Distribution of Weekday, Out-of-home, Non-work Activity Episode Start Times by Companion Type

Figure 2 Distribution of Weekend, Out-of-home, Non-work Activity Episode Start Times by Companion Type 
Table 1 Daily, Person-level Activity and Travel Participation: Descriptive Statistics

\begin{tabular}{|c|c|c|c|c|c|}
\hline & & \multicolumn{4}{|c|}{ 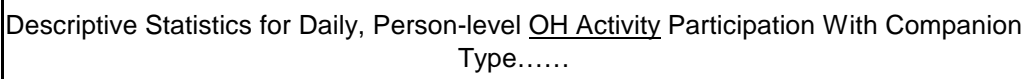 } \\
\hline & & Solo & Only $\mathrm{HH}$ members & $\begin{array}{c}\text { Only non-HH } \\
\text { members }\end{array}$ & Combination \\
\hline 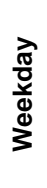 & $\mid \begin{array}{l}\%>=1 \text { Episode }^{1} \\
\text { Mean \# of Episodes } \\
\text { Mean Duration (mins) }\end{array}$ & $\begin{array}{c}74.54 \\
3.25 \\
384.89\end{array}$ & $\begin{array}{l}30.30 \\
2.27 \\
76.96\end{array}$ & $\begin{array}{r}49.03 \\
2.37 \\
117.65\end{array}$ & $\begin{array}{r}17.52 \\
2.03 \\
121.81\end{array}$ \\
\hline 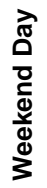 & $\mid \begin{array}{l}\%>=1 \text { Episode }^{1} \\
\text { Mean \# of Episodes }{ }^{2} \\
\text { Mean Duration (mins) }\end{array}$ & $\begin{array}{r}45.47 \\
2.34 \\
203.41\end{array}$ & $\begin{array}{r}35.42 \\
2.39 \\
141.29\end{array}$ & $\begin{array}{c}37.47 \\
2.80 \\
201.89\end{array}$ & $\begin{array}{r}28.78 \\
2.51 \\
201.44\end{array}$ \\
\hline
\end{tabular}

\begin{tabular}{||c||c|c|c|c||}
\hline \multicolumn{1}{|||||||}{} & \multicolumn{4}{c||}{ Descriptive Statistics for Daily, Person-level Travel Undertaken With Companion } \\
Type......
\end{tabular}

\begin{tabular}{|c|c|c|c|c|c|}
\hline 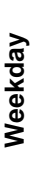 & $\begin{array}{l}\%>=1 \text { Episode }^{1} \\
\text { Mean \# of Episodes }{ }^{2} \\
\text { Mean Duration (mins) })^{2}\end{array}$ & $\begin{array}{r}71.75 \\
3.55 \\
60.96\end{array}$ & $\begin{array}{r}35.81 \\
3.09 \\
50.12\end{array}$ & $\begin{array}{r}20.99 \\
2.66 \\
52.94\end{array}$ & $\begin{array}{r}7.48 \\
2.30 \\
44.96\end{array}$ \\
\hline
\end{tabular}

\begin{tabular}{|c|c|c|c|c|c|}
\hline 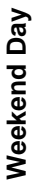 & $\begin{array}{l}\%>=1 \text { Episode }^{1} \\
\text { Mean \# of Episodes }{ }^{2} \\
\text { Mean Duration (mins) })^{2}\end{array}$ & $\begin{array}{l}47.18 \\
3.14 \\
50.34\end{array}$ & $\begin{array}{r}42.38 \\
3.45 \\
71.05\end{array}$ & $\begin{array}{l}20.61 \\
3.02 \\
69.20\end{array}$ & $\begin{array}{r}12.02 \\
2.70 \\
64.67\end{array}$ \\
\hline
\end{tabular}

${ }^{1}$ The numbers do not sum to $100 \%$ across columns (companion types) as individuals can undertake multiple episodes with different companion-type arrangements during the course of the day

${ }^{2}$ Averaged over persons undertaking at least one episode with companion-type in the corresponding column 
Table 2 Models for the Frequency of Daily, Person-level, Activity and Travel Episodes

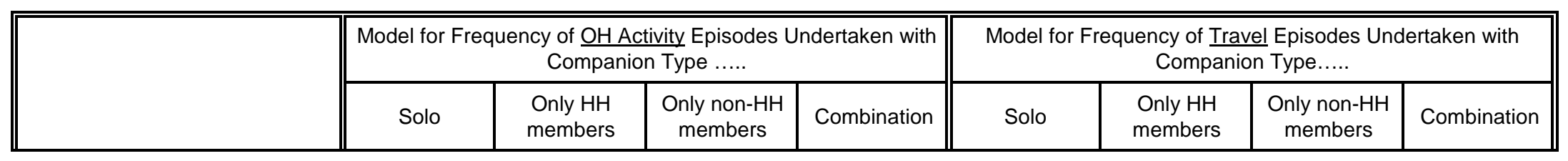

\begin{tabular}{|c|c|c|c|c|c|c|c|c|c|}
\hline \multirow{11}{*}{ 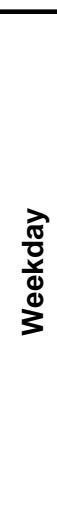 } & \multicolumn{9}{|c|}{ Explanatory Variables ${ }^{1}$} \\
\hline & Male & 0.143 & -0.346 & - & -0.289 & 0.081 & -0.343 & -0.038 & -0.280 \\
\hline & Student & 0.316 & -0.259 & 0.424 & - & 0.079 & -0.061 & 0.553 & - \\
\hline & Employed & 1.097 & -0.107 & 0.297 & -0.110 & 0.681 & -0.140 & - & -0.114 \\
\hline & Income & 0.014 & -0.006 & - & -0.010 & 0.010 & -0.012 & -0.005 & -0.013 \\
\hline & Single Person & 0.098 & $N^{2}$ & 0.138 & $N A^{2}$ & 0.247 & $N A^{2}$ & 0.072 & $N A^{2}$ \\
\hline & Married & -0.130 & 0.451 & -0.328 & 0.110 & -0.063 & 0.441 & -0.410 & -0.124 \\
\hline & Children Present & -0.072 & 0.722 & -0.084 & 0.401 & -0.088 & 0.722 & -0.103 & 0.374 \\
\hline & \multicolumn{9}{|l|}{ Model Fit } \\
\hline & 1-[ LL(B) / LL(0) ] & 0.091 & 0.370 & 0.242 & 0.579 & 0.101 & 0.269 & 0.560 & 0.767 \\
\hline & Number of cases & 17173 & 13894 & 17173 & 13894 & 17173 & 13894 & 17173 & 13894 \\
\hline
\end{tabular}

\begin{tabular}{|c|c|c|c|c|c|c|c|c|c|}
\hline \multirow{10}{*}{ 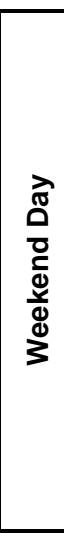 } & \multicolumn{9}{|c|}{ Explanatory Variables ${ }^{1}$} \\
\hline & Male & 0.135 & -0.222 & 0.048 & -0.244 & 0.178 & -0.215 & -0.050 & -0.294 \\
\hline & Student & - & 0.071 & 0.316 & 0.066 & - & 0.135 & 0.363 & - \\
\hline & Employed & 0.625 & - & 0.226 & - & 0.513 & - & 0.165 & - \\
\hline & Income & - & 0.013 & - & 0.006 & 0.005 & 0.009 & - & 0.009 \\
\hline & Single Person & 0.306 & $N A^{2}$ & 0.218 & $\mathrm{NA}^{2}$ & 0.375 & $\mathrm{NA}^{2}$ & 0.125 & $N A^{2}$ \\
\hline & Married & -0.158 & 0.679 & -0.633 & 0.218 & -0.266 & 0.736 & -0.747 & -0.089 \\
\hline & \multicolumn{9}{|l|}{ Model Fit } \\
\hline & 1-[ LL(B) / LL(0) ] & 0.278 & 0.286 & 0.351 & 0.372 & 0.246 & 0.196 & 0.570 & 0.651 \\
\hline & Number of cases & 17520 & 14120 & 17520 & 14120 & 17520 & 14120 & 17520 & 14120 \\
\hline
\end{tabular}

\footnotetext{
1 The threshold parameters have been suppressed to reduce clutter
${ }^{2}$ Activity-travel participation with household members not possible in the case of single-person housheolds
} 
Table 3 Companion-Type Choice Models for Out-of-Home Activity Episodes

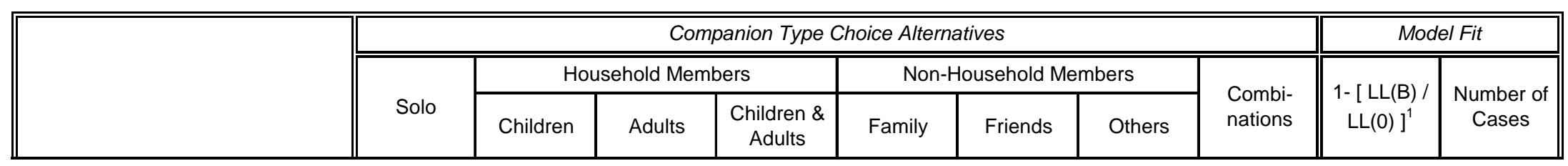

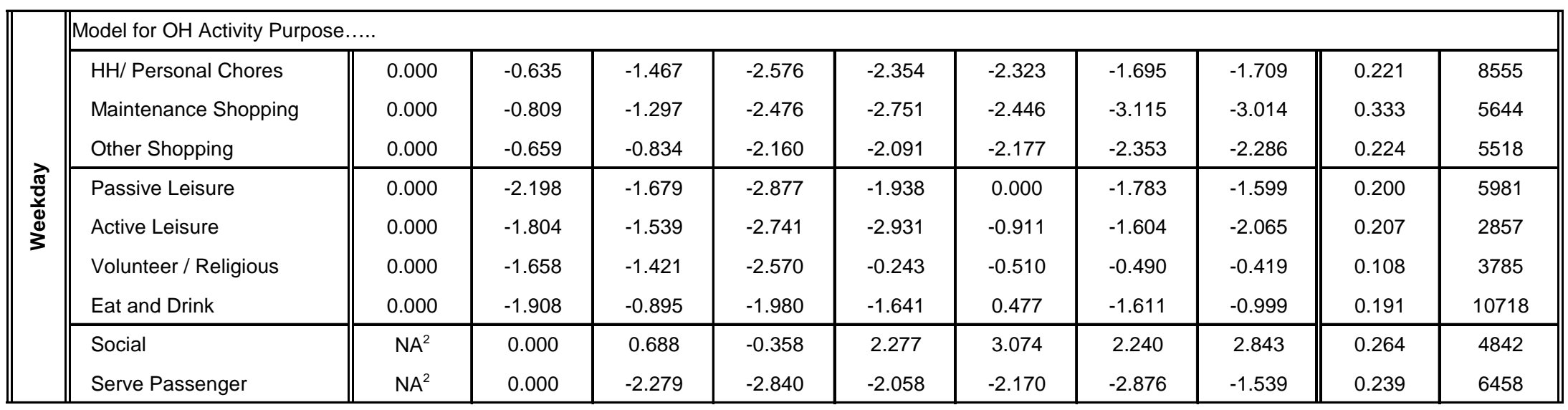

\begin{tabular}{|c|c|c|c|c|c|c|c|c|c|c|c|}
\hline \multirow{9}{*}{ 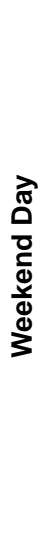 } & \multicolumn{11}{|c|}{ Model for $\mathrm{OH}$ Activity Purpose...... } \\
\hline & $\mathrm{HH} /$ Personal Chores & 0.000 & -0.468 & -0.915 & -1.121 & -1.427 & -1.696 & -1.778 & -0.722 & 0.221 & 6485 \\
\hline & Maintenance Shopping & 0.000 & -0.566 & -0.586 & -1.278 & -2.180 & -2.331 & -2.582 & -2.161 & 0.333 & 6190 \\
\hline & Passive Leisure & 0.000 & -1.062 & -0.500 & -1.300 & -0.757 & 0.000 & -0.931 & -0.162 & 0.200 & 5872 \\
\hline & Active Leisure & 0.000 & -0.985 & -0.710 & -1.448 & -1.929 & -0.520 & -1.138 & -0.824 & 0.207 & 2715 \\
\hline & Volunteer / Religious & 0.000 & -0.459 & 0.545 & 0.000 & -0.151 & 0.573 & -0.537 & 0.934 & 0.108 & 7091 \\
\hline & Eat and Drink & 0.000 & -0.443 & 0.079 & -0.300 & -0.443 & -0.342 & -0.297 & 0.243 & 0.191 & 9407 \\
\hline & Social & $N A^{2}$ & 0.000 & 0.692 & 0.374 & 2.217 & 2.446 & 1.785 & 3.260 & 0.264 & 7765 \\
\hline & Serve Passenger & $N A^{2}$ & 0.000 & -1.240 & -1.287 & -0.839 & -0.620 & -1.285 & 0.000 & 0.239 & 3451 \\
\hline
\end{tabular}

${ }^{1}$ For each activity purpose, a single model was estimated accommodating full segmentation by day of the week. The fit of this model is reported

${ }^{2}$ By definition, social and serve passenger episodes cannot be undertaken solo 
Table 4 Companion-Type Choice Models for Travel Episodes

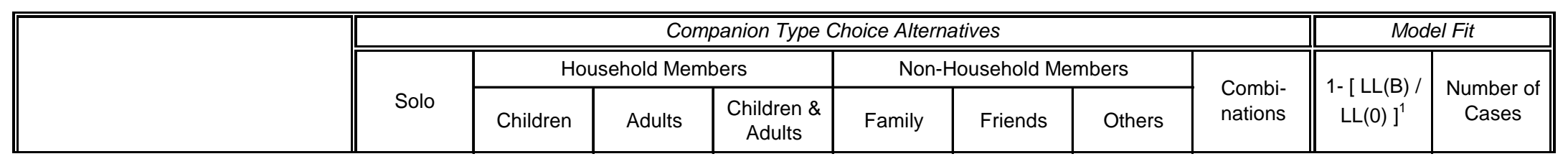

\begin{tabular}{|c|c|c|c|c|c|c|c|c|c|c|c|}
\hline & odel For Trips Whose & Activi & rpose is & & & & & & & & \\
\hline & Work/School & 0.000 & -3.619 & -3.319 & -5.411 & -5.039 & -3.030 & -4.447 & -5.215 & 0.717 & 10758 \\
\hline & Return Home & 0.000 & -1.013 & -1.808 & -2.897 & -3.517 & -3.223 & -3.928 & -3.430 & 0.413 & 24401 \\
\hline & $\mathrm{HH} /$ Personal Chores & 0.000 & -0.692 & -1.644 & -2.729 & -3.193 & -3.481 & -3.974 & -3.250 & 0.401 & 6040 \\
\hline & Maintenance Shop & 0.000 & -1.083 & -1.630 & -2.804 & -3.126 & -2.934 & -3.998 & -3.406 & 0.398 & 5388 \\
\hline$\frac{\pi}{2}$ & Other Shop & 0.000 & -0.995 & -1.172 & -2.451 & -2.474 & -2.686 & -3.261 & -2.794 & 0.297 & 5122 \\
\hline$\stackrel{\&}{\Delta}$ & Passive Leisure & 0.000 & -1.684 & -1.334 & -2.473 & -2.625 & -1.657 & -2.595 & -2.414 & 0.232 & 1820 \\
\hline & Active Leisure & 0.000 & -2.198 & -2.073 & -3.477 & -3.681 & -2.280 & -3.446 & -3.379 & 0.360 & 1322 \\
\hline & Volunteer / Religious & 0.000 & -1.410 & -1.637 & -2.951 & -1.880 & -2.493 & -2.982 & -2.789 & 0.303 & 2638 \\
\hline & Eat and Drink & 0.000 & -1.533 & -0.910 & -2.032 & -2.452 & -1.238 & -2.709 & -2.158 & 0.224 & 4339 \\
\hline & Social & 0.000 & -1.322 & -1.427 & -2.639 & -2.650 & -2.142 & -2.782 & -2.738 & 0.278 & 3192 \\
\hline & Serve Passenger & 0.000 & 0.525 & -1.436 & -2.190 & -1.579 & -1.639 & -2.437 & -1.227 & 0.216 & 6151 \\
\hline
\end{tabular}

\begin{tabular}{|c|c|c|c|c|c|c|c|c|c|c|c|}
\hline \multirow{12}{*}{ 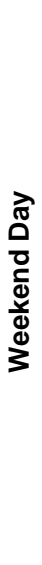 } & \multicolumn{11}{|c|}{ Model For Trips Whose Destination Activity Purpose is.... } \\
\hline & Work/School & 0.000 & -3.116 & -2.574 & -4.021 & -4.611 & -3.415 & -4.343 & -4.304 & 0.717 & 2858 \\
\hline & Return Home & 0.000 & -0.990 & -0.924 & -1.407 & -2.902 & -2.723 & -3.396 & -2.503 & 0.413 & 22975 \\
\hline & $\mathrm{HH} /$ Personal Chores & 0.000 & -0.626 & -1.238 & -1.350 & -2.417 & -2.727 & -3.181 & -2.038 & 0.401 & 3739 \\
\hline & Maintenance Shop & 0.000 & -0.932 & -0.962 & -1.557 & -2.581 & -2.766 & -3.255 & -2.543 & 0.398 & 5900 \\
\hline & Other Shop & 0.000 & -0.640 & -0.490 & -1.075 & -1.895 & -2.120 & -2.813 & -1.866 & 0.297 & 7072 \\
\hline & Passive Leisure & 0.000 & -1.230 & -0.638 & -1.322 & -1.829 & -1.148 & -2.035 & -1.333 & 0.232 & 2664 \\
\hline & Active Leisure & 0.000 & -1.403 & -1.278 & -1.806 & -2.686 & -1.538 & -2.225 & -1.929 & 0.360 & 1284 \\
\hline & Volunteer / Religious & 0.000 & -0.839 & -0.608 & -0.952 & -2.055 & -2.306 & -2.728 & -1.963 & 0.303 & 4660 \\
\hline & Eat and Drink & 0.000 & -0.660 & 0.214 & -0.371 & -1.378 & -0.932 & -1.896 & -0.757 & 0.224 & 5342 \\
\hline & Social & 0.000 & -0.918 & -0.576 & -1.092 & -1.997 & -1.843 & -2.573 & -1.682 & 0.278 & 4995 \\
\hline & Serve Passenger & 0.000 & -0.120 & -0.862 & -1.231 & -1.142 & -0.927 & -1.646 & -0.421 & 0.216 & 3351 \\
\hline
\end{tabular}

${ }^{1}$ For each trip purpose, a single model was estimated accommodating full segmentation by day of the week. The fit of this model is reported 
Table 5 Models for Out-of-Home Activity Episode Durations

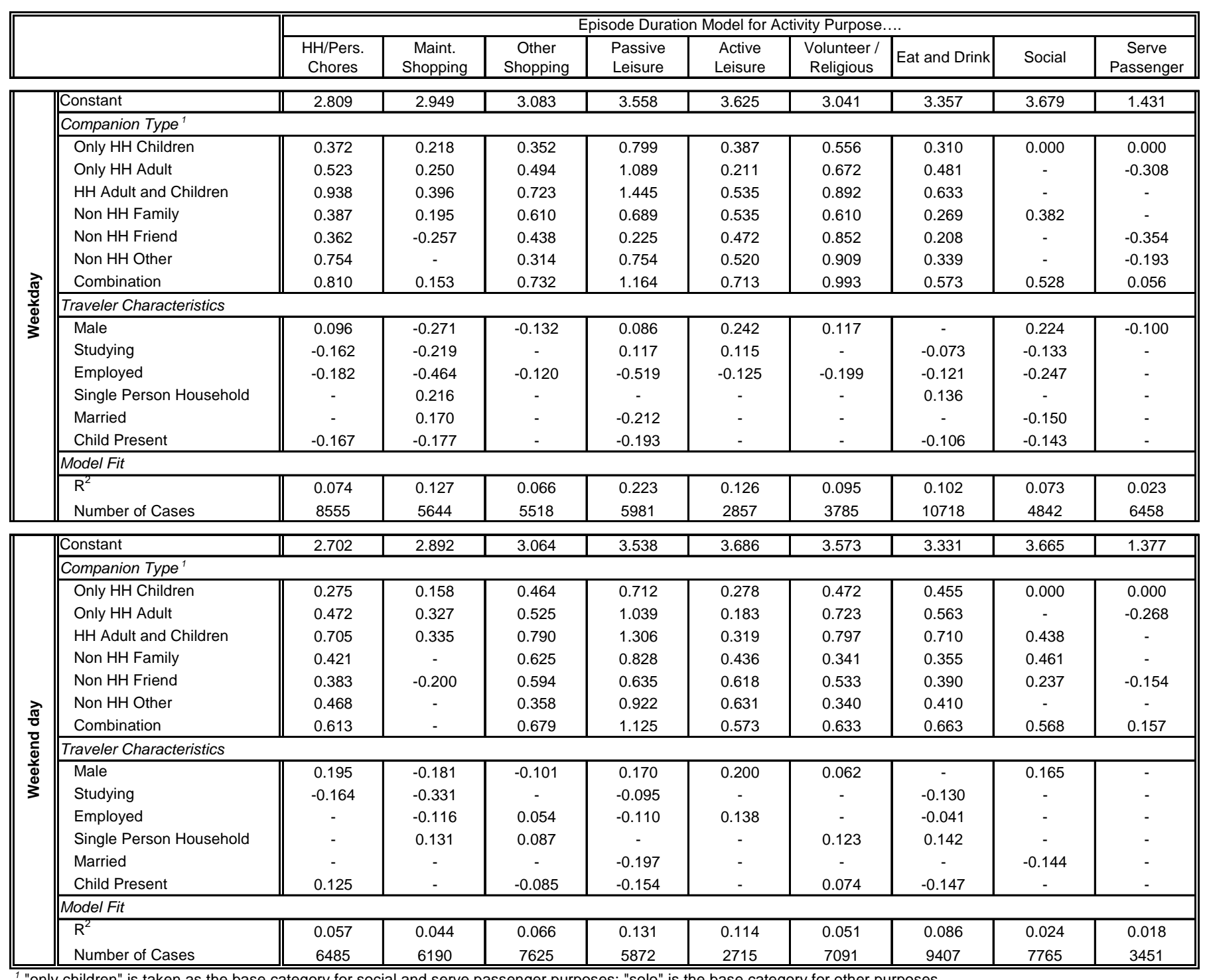

${ }^{1}$ "only children" is taken as the base category for social and serve passenger purposes; "solo" is the base category for other purposes 
Table 6 Models for Travel Episode Durations

\begin{tabular}{|c|c|c|c|c|c|c|c|c|c|c|c|c|}
\hline & \multicolumn{11}{|c|}{ Episode Duration Model For Trips Whose Destination Activity Purpose is. } \\
\hline & & Work & Return Home & $\begin{array}{c}\text { HH/Pers. } \\
\text { Chores }\end{array}$ & $\begin{array}{c}\text { Maint. } \\
\text { Shopping } \\
\end{array}$ & $\begin{array}{c}\text { Other } \\
\text { Shopping } \\
\end{array}$ & $\begin{array}{l}\text { Passive } \\
\text { Leisure }\end{array}$ & $\begin{array}{l}\begin{array}{c}\text { Active } \\
\text { Leisure }\end{array} \\
\end{array}$ & $\begin{array}{c}\text { Volunteer / } \\
\text { Religious } \\
\end{array}$ & Eat and Drink & Social & $\begin{array}{c}\text { Serve } \\
\text { Passenger }\end{array}$ \\
\hline \multirow{22}{*}{ 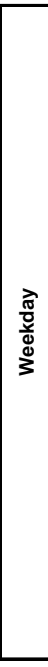 } & |Constant & 2.624 & 2.393 & 2.413 & 2.071 & 2.328 & 2.394 & 2.210 & 2.458 & 2.386 & 2.433 & 2.376 \\
\hline & \multicolumn{12}{|l|}{$\mid$ Companion Type $^{1}$} \\
\hline & Only HH Children & -0.344 & -0.187 & & - & 0.121 & - & - & & & - & -0.163 \\
\hline & Only HH Adult & -0.154 & 0.107 & 0.247 & 0.297 & 0.172 & - & 0.166 & 0.217 & 0.239 & 0.165 & 0.132 \\
\hline & HH Adult and Children & -0.284 & - & 0.123 & 0.276 & 0.224 & 0.187 & - & 0.187 & 0.257 & 0.207 & - \\
\hline & Non HH Family & & 0.143 & 0.275 & 0.210 & 0.137 & & 0.379 & 0.118 & 0.173 & 0.271 & 0.197 \\
\hline & Non HH Friend & -0.230 & 0.269 & 0.293 & - & 0.165 & 0.137 & 0.225 & 0.181 & - & 0.188 & 0.236 \\
\hline & Non $\mathrm{HH}$ Other & -0.152 & 0.086 & & 0.157 & 0.259 & 0.340 & 0.364 & - & - & 0.203 & 0.158 \\
\hline & Combination & -0.215 & 0.144 & 0.119 & 0.148 & 0.283 & 0.336 & 0.551 & 0.177 & 0.419 & 0.139 & -0.084 \\
\hline & \multicolumn{12}{|l|}{ Traveler Characteristics } \\
\hline & $\mid$ Male & 0.113 & 0.133 & 0.065 & 0.048 & 0.099 & 0.107 & 0.151 & 0.122 & 0.098 & 0.132 & 0.084 \\
\hline & Studying & -0.032 & -0.056 & - & -0.138 & -0.116 & -0.201 & - & -0.147 & -0.074 & -0.200 & -0.063 \\
\hline & Employed & - & 0.108 & - & -0.098 & -0.075 & 0.094 & - & - & -0.106 & - & - \\
\hline & Single Person Household & - & - & - & 0.179 & - & - & 0.172 & - & - & - & - \\
\hline & Married & - & 0.052 & - & 0.063 & -0.069 & - & 0.143 & -0.087 & - & - & - \\
\hline & Child Present & - & -0.062 & -0.095 & - & -0.085 & -0.117 & -0.102 & -0.084 & -0.110 & - & - \\
\hline & \multicolumn{12}{|l|}{ Travel Mode } \\
\hline & Walk/Bike & -0.867 & -0.681 & -0.710 & -0.475 & -0.780 & -0.857 & -0.662 & -0.895 & -0.800 & -1.011 & -0.372 \\
\hline & Transit & 0.628 & 0.744 & 0.861 & 0.813 & 0.887 & 0.647 & 0.302 & 0.295 & 0.742 & 0.579 & 1.112 \\
\hline & \multicolumn{12}{|l|}{\begin{tabular}{|l} 
Model Fit \\
\end{tabular}} \\
\hline & $\mathrm{R}^{2}$ & 0.095 & 0.078 & 0.073 & 0.051 & 0.074 & 0.132 & 0.091 & 0.082 & 0.112 & 0.144 & 0.046 \\
\hline & Number of Cases & 10758 & 24401 & 6040 & 5388 & 5122 & 1820 & 1322 & 2638 & 4339 & 3192 & 6151 \\
\hline \multirow{22}{*}{ 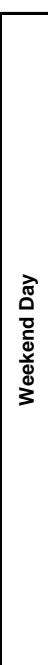 } & ||Constant & 2.352 & 2.413 & 2.284 & 2.136 & 2.296 & 2.569 & 2.355 & 2.388 & 2.411 & 2.464 & 2.397 \\
\hline & \multicolumn{12}{|l|}{$\mid$ Companion Type $^{1}$} \\
\hline & Only HH Children & - & 0.110 & 0.201 & 0.088 & 0.150 & 0.138 & - & 0.105 & - & 0.102 & - \\
\hline & Only HH Adult & - & 0.317 & 0.438 & 0.316 & 0.250 & 0.245 & 0.444 & 0.196 & 0.328 & 0.352 & 0.193 \\
\hline & HH Adult and Children & - & 0.365 & 0.412 & 0.462 & 0.370 & 0.368 & 0.464 & 0.189 & 0.336 & 0.401 & 0.240 \\
\hline & Non HH Family & & 0.276 & 0.311 & 0.280 & 0.232 & 0.125 & 0.519 & 0.201 & 0.233 & 0.268 & 0.286 \\
\hline & Non HH Friend & 0.217 & 0.359 & 0.255 & 0.443 & 0.211 & 0.273 & 0.463 & 0.156 & 0.267 & 0.263 & 0.309 \\
\hline & Non HH Other & & 0.338 & 0.343 & 0.172 & 0.349 & 0.322 & 0.441 & 0.163 & 0.373 & 0.369 & 0.357 \\
\hline & Combination & 0.348 & 0.404 & 0.406 & 0.394 & 0.368 & 0.493 & 0.502 & 0.313 & 0.344 & 0.455 & 0.295 \\
\hline & \multicolumn{12}{|l|}{$\mid$\begin{tabular}{|l} 
Traveler Characteristics \\
\end{tabular}} \\
\hline & Male & 0.066 & 0.076 & 0.076 & 0.093 & 0.063 & - & - & 0.045 & - & 0.077 & 0.133 \\
\hline & Studying & - & - & - & - & - & - & - & - & - & - & - \\
\hline & Employed & 0.178 & 0.031 & - & -0.099 & - & - & - & - & -0.053 & 0.079 & - \\
\hline & Single Person Household & - & - & 0.109 & - & - & - & 0.208 & - & - & - & - \\
\hline & Married & - & - & - & - & -0.058 & & - & - & - & -0.075 & - \\
\hline & Child Present & - & -0.099 & - & -0.123 & -0.076 & -0.143 & - & -0.059 & -0.064 & -0.125 & -0.093 \\
\hline & \multicolumn{12}{|l|}{ Travel Mode } \\
\hline & Walk/Bike & -0.986 & -0.733 & -0.782 & -0.484 & -0.918 & -0.863 & -0.874 & -0.947 & -0.778 & -1.217 & -0.944 \\
\hline & Transit & 0.900 & 0.833 & 0.801 & 0.600 & 0.739 & 0.803 & 0.623 & 0.395 & 0.660 & 0.436 & 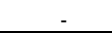 \\
\hline & \multicolumn{12}{|l|}{ Model Fit } \\
\hline & $\mathrm{R}^{2}$ & 0.102 & 0.080 & 0.085 & 0.059 & 0.077 & 0.130 & 0.156 & 0.079 & 0.072 & 0.178 & 0.049 \\
\hline & Number of Cases & 2858 & 22975 & 3739 & 5900 & 7072 & 2664 & 1284 & 4660 & 5342 & 4995 & 3351 \\
\hline
\end{tabular}

"solo" is the base category 
Table 7 Location Choice Models for Out-of-Home Activity Episodes

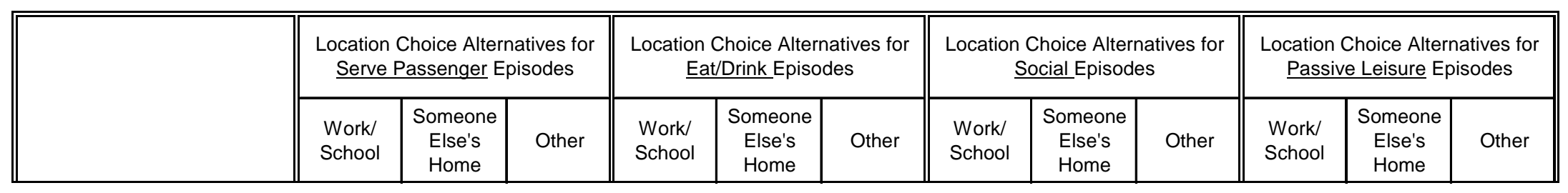

\begin{tabular}{|c|c|c|c|c|c|c|c|c|c|c|c|c|c|}
\hline & \multicolumn{13}{|c|}{ Non Household Companion Type } \\
\hline & Family & 0.000 & 1.162 & 0.739 & 0.000 & 2.171 & 2.187 & 0.000 & 3.365 & 1.421 & 0.000 & 2.804 & 1.536 \\
\hline \multirow{6}{*}{$\begin{array}{l}\frac{\pi}{0} \\
\frac{\mathrm{d}}{0} \\
\mathrm{~d}^{3}\end{array}$} & Friends & 0.000 & 2.792 & 2.183 & 0.000 & -2.817 & -0.953 & 0.000 & -0.293 & -0.390 & 0.000 & -1.339 & -1.659 \\
\hline & Other & 0.000 & 1.980 & 1.292 & 0.000 & -0.370 & 0.967 & 0.000 & 1.508 & 1.332 & 0.000 & 1.119 & 1.068 \\
\hline & Combination & 0.000 & 1.206 & 0.771 & 0.000 & 1.541 & 2.153 & 0.000 & 2.703 & 1.785 & 0.000 & 1.644 & 1.548 \\
\hline & Model Fit & & & & & & & & & & & & \\
\hline & $1-[\operatorname{LL}(B) / \operatorname{LL}(0)]^{1}$ & & 0.253 & & & 0.280 & & & 0.314 & & & 0.209 & \\
\hline & Number of cases & & 2400 & & & 6056 & & & 7340 & & & 3582 & \\
\hline
\end{tabular}

\begin{tabular}{|c|c|c|c|c|c|c|c|c|c|c|c|c|c|}
\hline \multirow{8}{*}{ 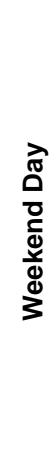 } & \multicolumn{13}{|c|}{ Non Household Companion Type } \\
\hline & Family & 0.000 & 4.325 & 3.714 & 0.000 & 3.874 & 3.934 & 0.000 & 5.221 & 3.260 & 0.000 & 3.613 & 2.843 \\
\hline & Friend & 0.000 & - & - & 0.000 & -0.654 & 0.625 & 0.000 & 1.581 & 1.475 & 0.000 & 0.457 & 0.378 \\
\hline & Other & 0.000 & 4.599 & 3.911 & 0.000 & 2.179 & 3.112 & 0.000 & 3.346 & 3.114 & 0.000 & 3.256 & 2.966 \\
\hline & Combination & 0.000 & 3.329 & 2.552 & 0.000 & 3.879 & 4.279 & 0.000 & 4.447 & 3.537 & 0.000 & 2.794 & 2.900 \\
\hline & \multicolumn{13}{|l|}{ Model Fit } \\
\hline & $1-[\operatorname{LL}(\mathrm{B}) / \mathrm{LL}(0)]^{1}$ & \multicolumn{3}{|c|}{0.253} & \multicolumn{3}{|c|}{0.280} & \multicolumn{3}{|c|}{0.314} & \multicolumn{3}{|c|}{0.209} \\
\hline & Number of cases & \multicolumn{3}{|c|}{2703} & \multicolumn{3}{|c|}{6056} & \multicolumn{3}{|c|}{4648} & \multicolumn{3}{|c|}{3351} \\
\hline
\end{tabular}

${ }^{1}$ For each activity purpose, a single model was estimated accommodating full segmentation by day of the week and the non household companion type. The fit of this model is reported 
Table 8 Time-of-Day Choice Models for Non-Work Activity Episodes

\begin{tabular}{|c|c|c|c|c|c|c|c|c|c|c|}
\hline & \multicolumn{8}{|c|}{ Time-of-Day Choice Alternatives (Before 7 AM is the "base") } & \multicolumn{2}{|c|}{ Model Fit } \\
\hline & $\begin{array}{c}7 \mathrm{AM}-9 \\
\mathrm{AM}\end{array}$ & $\begin{array}{c}9 \mathrm{AM}-11 \\
\mathrm{AM}\end{array}$ & $\begin{array}{c}11 \mathrm{AM}-1 \\
\mathrm{PM}\end{array}$ & $\begin{array}{c}1 \mathrm{PM}-3 \\
\mathrm{PM}\end{array}$ & $\begin{array}{c}3 \text { PM - } 5 \\
\text { PM }\end{array}$ & $\begin{array}{c}5 \text { PM - } 7 \\
\text { PM }\end{array}$ & $\begin{array}{c}7 \text { PM - } 9 \\
\text { PM }\end{array}$ & After 9 PM & $\mid \begin{array}{c}1-[\operatorname{LL}(B) \\
\operatorname{LL}(0)]\end{array}$ & $\begin{array}{c}\text { Number of } \\
\text { Cases }\end{array}$ \\
\hline
\end{tabular}

\begin{tabular}{|c|c|c|c|c|c|c|c|c|c|c|c|}
\hline \multirow{9}{*}{ 离 } & \multicolumn{11}{|c|}{ Model for Non-Work OH Activity Epsiodes Undertaken With Companion Type ... } \\
\hline & Solo & 0.605 & 0.948 & 1.321 & 1.058 & 0.934 & 0.745 & - & -0.600 & 0.057 & 19108 \\
\hline & Only HH Children & 1.935 & 0.766 & 0.998 & 1.158 & 1.766 & 1.529 & 0.651 & -0.623 & 0.095 & 5977 \\
\hline & Only HH Adults & 1.046 & 1.380 & 1.785 & 1.554 & 1.382 & 1.844 & 1.389 & 0.430 & 0.050 & 4224 \\
\hline & HH Adults and Children & 1.268 & 1.247 & 1.623 & 1.742 & 2.083 & 2.801 & 2.384 & 0.810 & 0.114 & 1582 \\
\hline & Non HH Family & 1.164 & 1.478 & 1.881 & 1.816 & 1.778 & 1.811 & 1.265 & 0.402 & 0.057 & 4184 \\
\hline & Non HH Friends & 0.237 & 0.822 & 1.567 & 0.869 & 0.554 & 0.629 & 0.485 & - & 0.057 & 11572 \\
\hline & Non HH Other & 0.842 & 1.149 & 1.420 & 1.191 & 1.217 & 1.320 & 1.088 & 0.544 & 0.029 & 4167 \\
\hline & Combination & 1.282 & 1.309 & 1.940 & 1.824 & 2.154 & 2.600 & 2.246 & 1.268 & 0.078 & 6108 \\
\hline
\end{tabular}

\begin{tabular}{|c|c|c|c|c|c|c|c|c|c|c|c|}
\hline \multirow{9}{*}{ 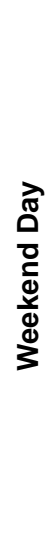 } & \multicolumn{11}{|c|}{ Model for Non-Work OH Activity Epsiodes Undertaken With Companion Type ... } \\
\hline & Solo & 0.867 & 1.370 & 1.377 & 1.163 & 1.045 & 0.818 & 0.176 & -0.211 & 0.055 & 12799 \\
\hline & Only HH Children & 1.460 & 2.510 & 2.622 & 2.513 & 2.325 & 2.161 & 1.511 & 0.684 & 0.093 & 3873 \\
\hline & Only HH Adults & 1.575 & 2.341 & 2.425 & 2.139 & 2.043 & 2.099 & 1.613 & 0.544 & 0.074 & 6567 \\
\hline & HH Adults and Children & 1.997 & 2.915 & 3.016 & 2.808 & 2.690 & 2.693 & 1.943 & 0.813 & 0.097 & 4413 \\
\hline & Non HH Family & 1.028 & 1.783 & 2.077 & 2.044 & 1.960 & 1.897 & 1.459 & 0.653 & 0.064 & 5722 \\
\hline & Non HH Friends & 0.172 & 0.825 & 0.949 & 0.870 & 0.772 & 0.881 & 0.733 & 0.425 & 0.019 & 8198 \\
\hline & Non HH Other & 0.753 & 1.584 & 1.584 & 1.410 & 1.416 & 1.441 & 1.146 & 0.758 & 0.038 & 4431 \\
\hline & Combination & 1.206 & 2.255 & 2.545 & 2.476 & 2.409 & 2.702 & 2.196 & 1.335 & 0.076 & 12682 \\
\hline
\end{tabular}


Table 9 Activity Episode Purpose Transition Matrix

\begin{tabular}{|c|c|c|c|c|c|c|c|c|c|}
\hline & \multirow[b]{2}{*}{ Current Episode Type } & \multicolumn{8}{|c|}{ Subsequent Episode Type } \\
\hline & & In Home & $\begin{array}{l}\text { Out-of-Home, } \\
\text { Solo }\end{array}$ & $\begin{array}{c}\text { Out-of-Home, } \\
\text { only HH } \\
\text { members }\end{array}$ & $\begin{array}{c}\text { Out-of-Home, } \\
\text { non HH } \\
\text { members }\end{array}$ & $\begin{array}{c}\text { Serve } \\
\text { Passenger }\end{array}$ & Travel, Solo & $\begin{array}{c}\text { Travel, only } \\
\text { HH members }\end{array}$ & $\begin{array}{l}\text { Travel, non } \\
\text { HH members }\end{array}$ \\
\hline \multirow{8}{*}{$\begin{array}{l}\frac{\vec{\pi}}{0} \\
\frac{8}{0} \\
3\end{array}$} & In Home & 86.93 & 0.00 & 0.00 & 0.00 & 0.00 & 7.83 & 3.77 & 1.47 \\
\hline & |Out-of-Home, Solo & 0.00 & 24.95 & 0.56 & 15.06 & 0.00 & 50.72 & 3.73 & 4.98 \\
\hline & |Out-of-Home, only HH members & 0.00 & 2.97 & 12.18 & 3.03 & 0.00 & 4.11 & 76.50 & 1.21 \\
\hline & Out-of-Home, non HH members & 0.00 & 28.00 & 0.65 & 18.24 & 0.00 & 19.44 & 8.08 & 25.59 \\
\hline & Serve Passenger & 0.00 & 0.00 & 0.00 & 0.00 & 0.00 & 38.09 & 39.05 & 22.86 \\
\hline & |Travel, Solo & 33.69 & 46.05 & 0.59 & 10.90 & 4.14 & 3.99 & 0.27 & 0.37 \\
\hline & |Travel, only HH members & 35.74 & 6.69 & 31.29 & 8.85 & 14.56 & 0.71 & 1.99 & 0.17 \\
\hline & |Travel, non HH members & 22.59 & 12.30 & 0.47 & 47.14 & 12.54 & 1.77 & 0.27 & 2.92 \\
\hline
\end{tabular}

\begin{tabular}{|c|c|c|c|c|c|c|c|c|c|}
\hline \multirow{8}{*}{ 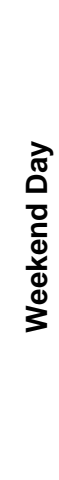 } & In Home & 87.16 & 0.00 & 0.00 & 0.00 & 0.00 & 5.48 & 5.12 & 2.24 \\
\hline & |Out-of-Home, Solo & 0.00 & 20.39 & 1.20 & 10.53 & 0.00 & 58.59 & 4.90 & 4.39 \\
\hline & ||Out-of-Home, only HH members & 0.00 & 1.23 & 14.53 & 3.84 & 0.00 & 1.81 & 77.36 & 1.23 \\
\hline & ||Out-of-Home, non $\mathrm{HH}$ members & 0.00 & 6.08 & 1.53 & 29.79 & 0.00 & 14.34 & 13.16 & 35.12 \\
\hline & |Serve Passenger & 0.00 & 0.00 & 0.00 & 0.00 & 0.00 & 29.99 & 30.71 & 39.30 \\
\hline & ||Travel, Solo & 37.60 & 39.23 & 0.86 & 15.32 & 3.06 & 3.19 & 0.35 & 0.39 \\
\hline & Travel, only HH members & 36.23 & 3.28 & 40.10 & 13.41 & 3.94 & 0.38 & 2.55 & 0.11 \\
\hline & |Travel, non HH members & 23.52 & 3.78 & 0.72 & 58.04 & 9.35 & 0.91 & 0.34 & 3.34 \\
\hline
\end{tabular}


Srinivasan and Bhat
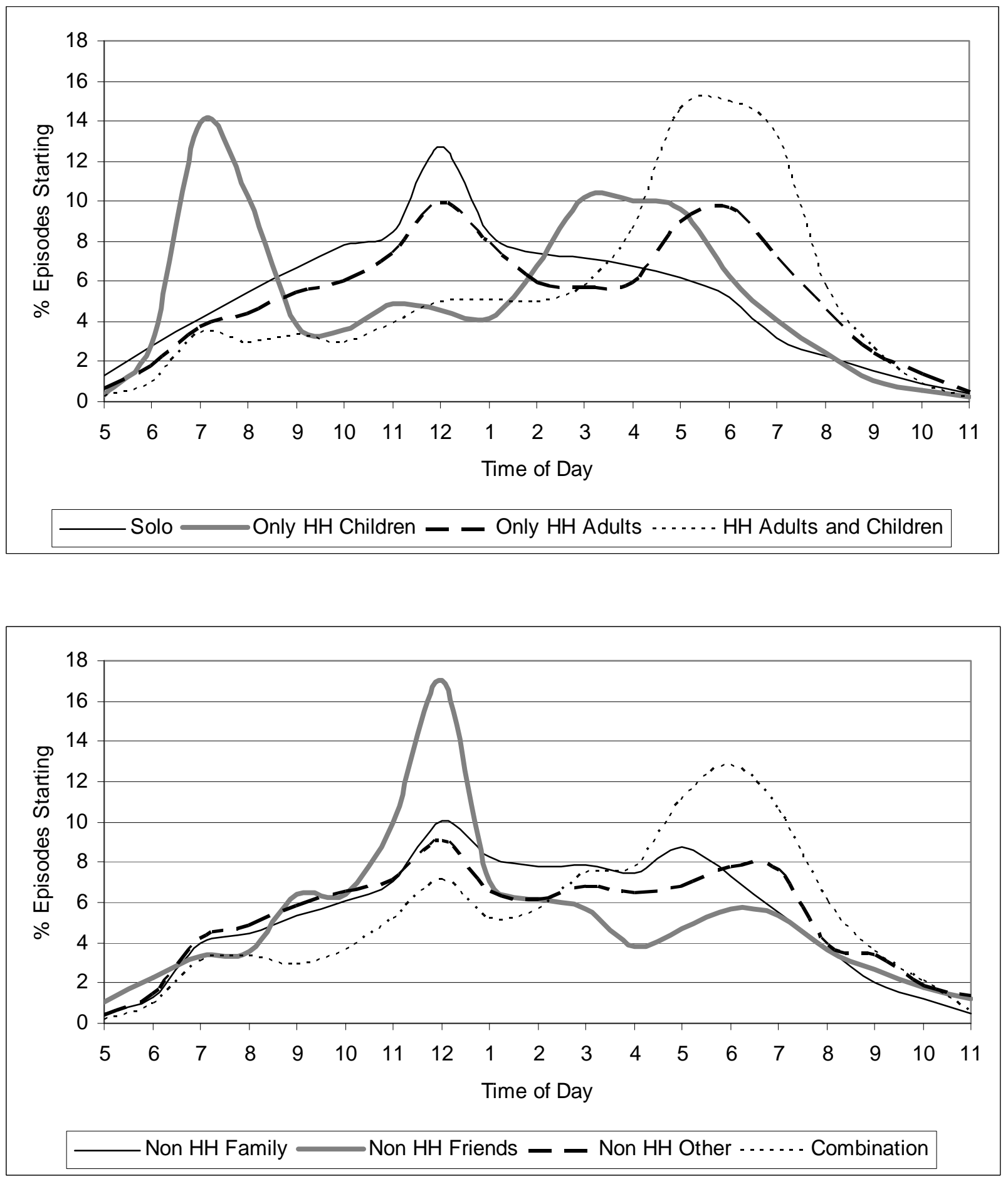

Figure 1 Distribution of Weekday, Out-of-home, Non-work Activity Episode Start Times by Companion Type (top graph is for solo episodes and joint episodes with household members only, bottom graph is for joint episodes with non household members) 
Srinivasan and Bhat
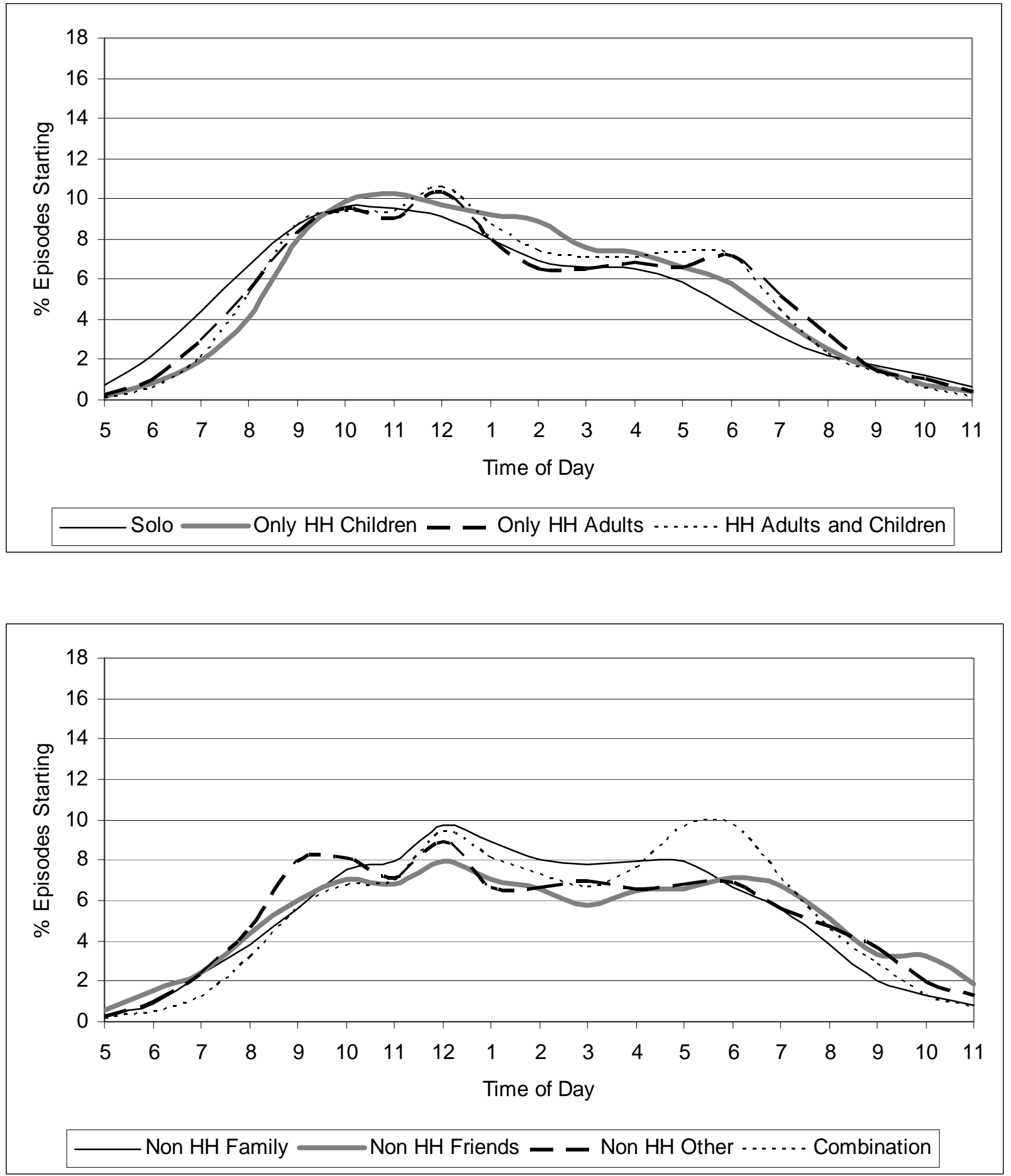

Figure 2 Distribution of Weekend, Out-of-home, Non-work Activity Episode Start Times by Companion Type (top graph is for solo episodes and joint episodes with household members only, bottom graph is for joint episodes with non household members) 